\title{
MAINTAINING MASCULINITIES
}

Adam Doering and Clifton Evers

\section{Abstract}

This article examines the local practices, histories, and transnational circulation and exchange of gender ideologies within Japanese surfscapes. A focus on gender in relation to Japanese surf culture is critical as the ways surf spaces in Japan are governed and/or have changed in recent years has as much to do with transnational gender surf ideologies as with its domestic gender norms. More specifically, we examine how gendered ideologies in Japan are mobilised in particular ways depending on the conditions of possibility - the cultural, social, geographical, historical, and networked elements - that comprise any given surfscape. To draw attention to the complexities involved in the relationship between space, place and gender in Japan the enquiry is undertaken in a highly localised, territorial, and big-wave surf site in Wakayama Prefecture and surrounding Kansai region. This site has been chosen because of how it localises a unique mode of trans-Pacific surf culture, thereby offering insight into the nuances, issues and strategies of social change as surfing continues to evolve in the region. The aim of the analysis is two-fold. The first is contextual, highlighting the importance of the culturally and site specific character of how surf culture and gender relations are assembled in the Japanese context. The second is to offer insight into the specific histories and transnational relationships informing the gendered practices of surfing in Japan today. The intention is to highlight the diversity of surf cultures throughout East Asia and the different ways surfing lifestyles are localised in relation to socio-political-ecological placemaking and gender.

Keywords: surfing, gender, masculinity, lifestyle sports, Japan, East Asia

\section{Introduction}

The inclusion of surfing as a demonstration sport in the Tokyo 2020 Olympic Games has renewed interest in Japan as a surf destination. Apart from sporadic mentions and contributions in English, little has been comprehensively written about Japan's diverse surfing histories, cultures, destinations and transnational networks either in English (Clark, 2011; Doering, 2018a, 2018b; Laderman, 2014, 2016; Mizuno, 2018; Moore, 2010; Warshaw, 2010; Westwick \& Neushul, 2013) or Japanese language (Kobayashi, 2013; 
Running header: Maintaining masculinities

Kobayashi et al., 2011, 2012; Konagaya, 2005, 2009; Mizuno, 2002, 2007, 2015; Murata, 2017). This is somewhat surprising given Japan is often acknowledged alongside America, Hawai'i, Australia, and Brazil as an established surf nation (O’Brien \& Ponting, 2013), and that the Tokyo 2020 Olympics will mark 60 years of Japanese surf history.

When Japan's surf culture is acknowledged, both Western media and academia have a tendency to characterize it as a quirky niche-market within the broader global surf industry. Amateur historian and author of the Encyclopedia of Surfing, Matt Warshaw (2010) writes, "Japanese pros... have made little or no impression outside of their country. Trade, industry, and commerce - this is what Japan soon meant to the surf world at large" (p. 326). Warshaw (2010) goes on to detail the history of this "fairly bizarre surf nation" in terms of its role in the global wetsuit and surfboard consumption and production, surf retail, and the International Professional Surfers (IPS) surf competitions held in Kantō region (p. 324). ${ }^{1}$ Academic writing has had the same effect of reinforcing a commerce-centric and quirky discourse of Japanese surf culture when they draw attention to the development of wavepool technology, specifically the Seagaia Ocean Dome in Miyazaki Prefecture (Ponting, 2017; Westwick \& Neushul, 2013) without offering historical insight into the surf history that enabled its production in the first place (see Doering, 2018a). Western corporate sponsored surf movies further frame Japanese waves as a space for global surf industry production and consumption, offering little commentary or representation of the Indigenous surfing communities throughout Japan. ${ }^{2}$

Our study of Japan fits well with how surf tourism and surf culture are being examined outside North American, Australasian, and Western European contexts (for a summary see the Introduction of Hough-Snee \& Eastman, 2017). There are varied and complex histories that comprise global surf culture today, involving co-constituting and conflicting local and global tendencies (Anderson, 2014; Comer, 2010; Laderman, 2014; Usher \& Kerstetter, 2015). Such dynamics play out in relation to multiple social identity axes of gender, race, ethnicity, class, age, (dis)abilities, religion, and sexuality (Thorpe \& Olive, 2016). To understand a local surf setting involves exploring how places and subjectivities are shaped by, as well as shape, contemporary global surf culture. We would like for the research here to contribute to efforts to de-colonise surfing (Ingersoll, 2016; McGloin, 2017; Gilio-Whitaker, 2017; Thompson, 2017).

The article begins by outlining the literature regarding surfing in relation to gender and place. We then offer a brief history of surfing in Japan with a specific focus on the ways gender relations have transformed through two phases of Japan's surfing development. Our 
focus on gender is important because of how it has, as we will show, been central to how surfing places have uniquely emerged, changed, and are interpreted in Japan. The article then turns to an analysis of a highly territorial, big wave surf scene in Wakayama located within the broader Kansai region. The aim of the analysis is two-fold. First is contextual, highlighting the how place specific local dynamics of global surf cultures play out within the Japanese context. The second aim is to offer an analysis of a transnational process underpinning the gendering of a local surfscape, as the sport continues to grow and expand globally. It is a transnational reading of the situation that follows in the wake of the work of Holly Thorpe (2014) who considers transnational mobilities - culturally and materially - of action sports. Specifically we are guided by three research questions: How are surfing masculinities maintained in a Japan's transforming and globalising surf scene? How do Japanese surfer identities reinvent and legitimate conventional gender roles in times of increasing diversification and mobility? And what narratives, ideologies and discourses help legitimate the maintenance of surfing masculinities in transnational Japan? We also aim to highlight the temporally and spatially extended exchanges that connect people, ideas and practices by way of trans-Pacific surfing mobilities thereby moving away from the common narrative of West-to-East dissemination (Moore, 2010). We argue it is critical to pay attention to the heterogeneity of surfing spaces and places throughout East Asia and the specific ways surfing lifestyles are experienced, as well as connected to elsewhere.

\section{Producing "surfscapes": Space, place, gender}

Borrowing Appadurai's (1996) lexicon, we employ the term "surfscape" to examine how global cultural flows of surf sites are produced through a complex entanglement not only of space and place, but also gender. There is a growing literature about surfing in relation to space, place and gender. They are co-constitutive. Place signifies here the particularities of inhabiting articulated spatio-temporal attachments at a location e.g. values, sensations, practices, objects, biographies (Massey, 1994). Importantly, we note that there is a concurrent multiplicity to places given arrangements temporalilty. So, if we think of gendered emphases, privileges, and marginalisations we can understand them as provisionally arranged during "particular moments ... which have a spatial form" (Ibid, p. 120). Gender orders mobilise in particular ways depending on the conditions of possibility - the cultural, social, ecological, material, economic, historical, and technological elements - that comprise any given surf location. Given the dynamism of this process there emerges the possibility for non-normative gendered articulations disruptive to the status quo. A number of studies have examined how 
Running header: Maintaining masculinities

high profile surfing places have been dominated, occupied, and controlled by men and masculine discourses which foster particular hegemonic expectations, behaviours, skill-sets, values, emotional regimes, technologies, ecologies, and histories (Evers, 2009, 2018; Ford \& Brown, 2006; Mizuno, 2002; Waitt \& Warren, 2008; Warren \& Gibson, 2014). We understand 'masculinities' here as multiple mutating socially and culturally specific arrangements of institutions, biology, spaces, practices, and values that manifest as differently privileged formations that may be singularities but also function transversally as commonality (Donald, 2018; Watson, 2015). ${ }^{3}$ This privileging of surfing masculinities continues to marginalise, devalue, and trivialise women's experiences and their accomplishments despite their increased participation and visibility across the world. Despite this constraint recent research has begun to show how women transform surfscapes and engage in their own place-making (for example, see Comer, 2010; Fendt \& Wilson, 2012; Knijnik et al., 2010; lisahunter, 2018; Olive et al., 2016; Olive 2016; Roy, 2014). Alternatives are being "carved out" (Comley, 2016, p. 1289). However, the constituting of gendered surfscapes throughout East Asia is to-date is underdeveloped. This limitation blocks more inclusive knowledge formation that can contribute to undermining a patriarchal dominance of surfing.

The surfscape of this study is located in Wakayama Prefecture and the Kansai region-a highly localised, territorial, and big-wave surf site in Wakayama Prefecture and surrounding Kansai region — where the first author has been working, living, surfing and conducting ethnographic research since 2016. The fieldwork comprises a compilation of media analysis, participant observation, semi-structured interviews, ethnographic field notes, social media discussions, post-surf discussions, and informal conversations in the water. Participant observation does involve going surfing, as this is one way we connected to and gained access to people and places that led to 'snowballing' opportunities for interviews, as well as observation of social and cultural dynamics that happen in the sea and not just on land (Evers, 2006, 2016). Twelve in-depth and semi-structured interviews were conducted with local professional, recreational, and beginner surfers who were asked to discuss their experiences and understandings of gender issues, localism and the cultural circulation of Hawaiian and Japanese surf cultures. The interviews comprised six men ranging in age from 34 to 68 and six women between the ages of 18 to 58 . The recorded interviews lasted from fifty minutes to one hour and twenty minutes. Just as important, however, the insights gained from this formal research process were repeatedly 'tested out' in everyday conversations with the participants in the surf, on the beaches and in the parking lots. To gain additional 
Running header: Maintaining masculinities

understandings of the trans-Pacific relations being explored interviews and conversations were also conducted with two professional big wave surfers from Hawai'i and one Indigenous Hawaiian surfers visiting Wakayama between 2017 and 2018. Informal conversations were also had with Japanese, Japanese-Hawaiian surfers, Indigenous Hawaiian surfers, and Japanese surf tourists during a visit to Oahu in March 2017.

The two authors discussed the data gathered from the field and inductively identified thematics, although we note that we are not trying to generalize from the findings but identify key influences on a specific state of affairs that others may compare with in their own studies so that a collaborative arrival at generalisability can be achieved in the future (Braun et al., 2016; Smith, 2018). The aim here is more humbly to offer localised and contextual insights into the issues and strategies of social change and continuity as surfing expands and transforms within the Japanese context.

\section{Surfing in Japan}

Traditional wave riding in Japan dates back to the use of small wooden body boards called itago during the Edo period (1603-1868) (Kobayashi, et al. 2012; Kobayashi, 2013; Moore, 2010; Ohkawa, n.d.). However, the diffusion of modern surfing came in two waves. The first beginning in the 1950s when first-generation Japanese surfers describe being exposed to surf imagery through the Western cultural media, specifically images in The National Geographic (Kobayashi et al., 2012; Kobayashi, 2013) and Life Magazine (Moore, 2010). As the popularity of surfing in the U.S. at the time reached new heights following the release of the film Gidget (1959), the early1960s saw a rapid increase of American soldiers based out of the Yokosuka naval base, located just 65 kilometres south of Tokyo, bringing fiberglass longboards on their military deployments to surf the breaks of Shōnan and Chiba. Japanese surfing in the Kantō region developed from informal person-to-person communication between Japanese youth and American soldiers (Kobayshi, 2013). By 1965, the National Surfing Association (NSA) was formed with an estimated total of 300 surfers from Kanagawa, Chiba and Tokyo Prefectures (Konagaya, 2005). After just five years the number of surfers is said to have grown to an estimated 50, 000 surfers by 1970 with representation from every coastline in Japan (Konagaya, 2005).

The second wave of surfing's popularity in Japan peaked between 1979 and 1983 amidst a steadily rising economy that began encouraging leisure as an important part of the nation's economic development (Konagaya, 2005). Surfing became fashion as magazines like Popeye and Oily Boy helped popularise the lifestyle amongst the mainstream youth 
Running header: Maintaining masculinities

(Konagoya, 2005, Mizuno, 2018). New terminology, the oka-safa, was established at this time to distinguish dedicated surfers from the fashionable ones (Mizuno, 2018). Oka is usually expressed by the character 陸, meaning land, implying that oka-safa are 'land surfers' who do not even go to the beach. During this second phase surfing became normalised. The mass media began reporting the rapid rise of surfers heading to small coastal communities as safin kogai, meaning 'surfing pollution' (Konagaya, 2005). At this time news reports accentuate the 'bad manners' and aggressive attitude of local surfers (Konagaya, 2005) as first-generation surfers began responding to the rapid increases in the number of city surfers flooding countryside surf breaks throughout Japan (Konagaya, 2005; Mizuno, 2007).

By the end of the 1980s the economic bubble had come to an end. Referred to as ushinawareta nijūnen, meaning 'twenty lost years' (1991-2010), surf culture and surf industry started to feel the effects of the economic downturn. But 'lost years' for whom? Mizuno's $(2002,2007,2015,2018)$ work demonstrates the twenty lost years were an important time in terms of reimagining the gender relations in Japanese surf culture, especially with the arrival of female bodyboarders during the 1990s. Mizuno (2002) identifies four recent trends that are redefining Japanese surfing cultures with respect to gender; a sharp increase in female surfers, the introduction of male bodyboarders, the shifting trend away from a group surf culture towards an individual practice, and an increasing emphasis on 'localism. ${ }^{4}$ However, despite shifting trends, many argue lifestyle sports in Japan continue to be governed by patriarchal social hierarchies and masculine discourses (Manzenreiter, 2013; Mizuno, 2002, 2018). As Mizuno (2018, p.74) argues, "Even with the passage of time and even though gender relations of the whole culture have changed, the modern form of surf culture has maintained a masculine character." The following examination of surfing in Japan provides broader insights into the ways gendered hegemony adapts to shifting histories, pressures, and expectations.

\section{Wakayama: A peri-urban and big wave surfscape}

The Kansai region of Japan is an interconnected regional network comprising the prefectures of Mie, Nara, Wakayama, Kyoto, Osaka, Hyōgo and Shiga, and sometimes Tokushima, Tottori and Fukui. Combined, Kansai is home to over twenty-million people. Situated on the Pacific side of this regional network is Wakayama City, a peri-urban transition zone bordered at the north by Osaka City and to the south by small fishing villages, sheltered bays, and highly localised point breaks and reefs found along the Kii Peninsular. 
Running header: Maintaining masculinities

Located just over one hour from Osaka City centre, and two hours from Kobe and Kyoto is the birthplace of Kansai area surfing, Isonoura Beach Park (Isonoura kaisuiyokujyo) in Wakayama City (Figure 1). Affectionately referred to as "Isoko" by the local surfers, the proximity to several major urban centers and a small beach area approximately 150-200 meters in width and just over 1000 meters in length has made the beach infamous for being Japan's most densely populated surf location. As one member of the Wakayama Surf Association described the situation in earnest, "Isoko is the busiest surf spot in the world."

\section{$<$ FIGURE 1>}

The majority of surfers in Isonoura are not 'local' in the conventional defining of the term. Despite travelling over $40 \mathrm{~km}$ — a common definition surf tourists (Buckley, 2002) Isonoura is a home break to a large number of Osaka City surfers. ${ }^{5}$ In terms of the gender demographics, the same survey roughly estimates visitors who drove to the beach comprised 77.6\% male, 8.8\% female, and 13.6\% unknown (Iwata, 2010). During the 1980s Wakayama saw a rapid increase in surfers, growing parking costs, difficulties of driving to the beach, and general overcrowding. Kanagawa (2018) suggests this 'surfer pollution' created an environment where many independent female travellers began going overseas for sea, surf, and more free space. Hawai'i was a dominant destination of choice (Yaguchi \& Yoshihara, 2004). The rapid rise in surfing's popularity transformed the gender relations of surf in important ways (Konagaya, 2005; Mizuno, 2007, 2018). Mizuno (2007) argues two factors, a diluted subcultural identity caused by over-commercialisation combined with the practical need for local surfers and coastal communities to respond to "surfing pollution", encouraged a more aggressive and exclusionary attitude of surf break governance at the local level. This produced a hegemonic masculine surfscape whereby women were not explicitly excluded, but the difficulties getting to the surf combined with increasingly aggressive attitudes became a deterrent for female participation. Mizuno suggests this ultimately culminated in a strong "locals first" identity characterised by a patriarchal surf hierarchy embodied through the presence of male 'surf bosses'. This social dynamic continues to inform the relations of Kansai area surf break governance today.

Physical geography also plays a critical role in the cultural production of Wakayama's hegemonically masculine surfscape. Ocean swell is almost entirely dependent on the typhoon season, which lasts a few short months between July and September. This makes the waves the waves in Wakayama inconsistent, but when they do arrive they can be some of the 
Running header: Maintaining masculinities

biggest waves in Japan. Wakayama's southern surfing locations face southeast, meaning the large typhoons swells that travel along the north-flowing Kuroshio Current hit the coastline head-on. Consequently, Wakayama has come to be regarded as the home of some of Japan's best big wave surfers. There is a tradition of men dominating the big wave scene at this site due to the masculine valuing and framing of risk and respect. This does not mean women do not surf big waves but rather the scene is dominated by men and their gendered perspectives. Sachie, a woman surfer in her late fifties who only started surfing 15 years ago despite being described as the club's longest standing members - a history lasting over four decadesexplains how hearing the conversations around the surf shop of big waves contributed to her feeling that surfing "was a man's sport. It's dangerous!"6

Further, as there are no waves during the winter, surf travel is a necessity for the dedicated Wakayama surfer. In the winter, Wakayama and Kansai surfers "go wave hunting", travelling northwest to the Sea of Japan or making an annual pilgrimage overseas, commonly to Hawai'i (Nakano, 2018, p. 52). This surfer mobility also shapes the gender relations of the region, as we examine later, the networked relations with the North Shore of Oahu Hawaiian surf scene can at times reinforce a masculine hegemony tied to big wave surfing.

Wakayama's peri-urban surfscape is characterised as a context where waves are in high demand and in short supply, remains dominated by a male demographic and masculine hegemony, and requires both extensive regional and international mobility to maintain a 'serious leisure' surf lifestyle (Stebbins, 1982). We now turn our analytic attention to two important historical and cultural themes that most strongly underpin the maintenance of masculine hegemony in the region: hierarchal relationships (joge kankei) and territorial consciousness (nawabari ishiki), before examining the transnational networks between Wakayama and the North Shore that also frames the gender order in this Japanese surfscape.

\section{Surf bosses, social hierarchy and the making of masculinities}

Surf spots in the Kansai region and Wakayama are commonly associated with and informally governed by charismatic personalities of first-generation male surfers who began surfing in the mid to late 1960s. It is common to hear these first-generation surfers referred to as shachō, legend (rejendo), or simply boss (bosu). Social status and access to surf are afforded through networked relations with and between surf bosses. To surf in Wakayama, or even more simply to get to the surf and find a parking spot, often requires a two-fold process of being introduced and maintaining good social relations with a surf shop, surf bosses, or local surf association (kumiai). Kazu, a professional big-wave surfer, whose father is 
Running header: Maintaining masculinities

regarded as an influential first-generation surfer in the Kansai area, describes the process like this,

If a known person introduces someone [that means] this person is ok. They feel safe and assured because through an introduction they know the level of the surfer you will be. In that way, local surfers remain vigilant. They worry for the safety of other surfers, and are concerned that the new surfer may get into an accident or will bring trouble. [author translation]

This cultural practice surf break hierarchy has important implications for the gendering of Wakayama's surf culture.

Interviews with women surfers in Wakayama offer some insights as to why. Seina, a 23-year old female Wakayama surfer explains that out of the group of forty to fifty core club members and over one-hundred loosely affiliated surfers who she surfs with, there are only four or five active women surfers. In addition to costs associated with getting to the surf that act as a barrier to participation and create a dependency on men (i.e. parking, obtaining a driver's licence, owning a car, and paying for expensive toll roads), Seina, a contest winning stand-up paddleboarder, tells of how she stopped going to one surf break because the surf boss persistently told her how dangerous it was to surf. The surf boss looking out for her safety. From Seina's perspective the persistent patronising discourse of danger and safety employed by the local surf boss made her unwilling to return to that surf space again. Women surfers experience similar patronising experiences in Australia (Olive et al., 2015). It was reported by women surfers that a key problem is the dominant male-networked surf relations whereby if issues or misunderstandings emerge, it is often the women who stop surfing or have to go somewhere else to surf. Mizuno (2002) argues this is precisely how Japan's surfing social structure remains "patriarchal" in the sense that such reginal networks comprise "a hierarchal relationship between men, where almost no women are included" (Ibid, p. 45). Through such hierarchal relations embodied in the presence of surf bosses access to less crowded waves in region means maintaining good relations with the male-governed networks and associated social hierarchies.

\section{Territorial consciousness [nawabari ishiki]: A traditional fisherman's mentality}

Surf bosses typically govern a relatively small local area however territories are regionally interconnected. Kazu acknowledges that although localism is common practice throughout Japan and the broader surf world, Wakayama has an especially strong 
Running header: Maintaining masculinities

sense of territoriality. Attempting to explain Wakayama's surfing territoriality, Kazu suggests a simple starting point for noticing the extent of Wakayama's territorial surf culture is to look at the annually published Japanese surf guide, "Beach Combing Magazine" (BCM, 2018). Although one sees a map of the vast Kii Peninsular only Isonoura Beach Park is listed. Kazu offers a possible explanation,

The traces of the past still exist. Wakayama used to be mostly fishing villages filled with fisherman. A really strong sense of nawabari ishiki [territorial consciousness] still exists. Seriously, there are a lot of top, famous world class, waves here. As expected, the reason these ones aren't on the maps is because people there think, "orera no umi ya" [This is our ocean]. Everyone here has this really strong territorial consciousness. [author translation]

Access to the waves in Wakayama are legitimated by this discourse and practice of nawabari ishiki [territorial consciousness]. The term nawabari ishiki literally translates to the roping off a specific territory and the marking out of territorial boundaries. It is a term most commonly used to explain the demarcation of a group's sphere of influence over a particular area (McVeigh, 2013; Austin, 2009). In the past, this encouraged a unified awareness of who could and could not use the common pool resource such as fisheries and forests within which unregulated use was strictly prohibited. Today, this traditional fisherman's territorial consciousness is used as a legitimating discourse and cultural practice within the surfers' attitudes towards surf zone governance. ${ }^{7}$ The discourse of 'traditional territoriality' functioning to legitimate exclusionary practices.

During the first author's time in the field, phone calls were made between surf bosses hundreds of kilometres away to provide access to highly localised surf spots, to check on visiting surfers - including the author - to see if they were connected to a local surf shop from where they came, and to keep the network of surf bosses informed as to whether or not visiting surfers behaved. One professional non-indigenous big wave surfer from Hawai'i describes an experience in Kansai where he witnessed one surfer "dropping in" - taking another surfer's wave out of order-damaging the surf board and sparking a dispute. The issue was only resolved when the respective surf bosses representing the surfers called each other to sort it out. Somewhat nostalgically he further explains, "That's how it works. There's a layer out there that doesn't happen at home [Hawai'i] anymore". These regionally networked surf shops comprise the underlying layer of surf space governance in the region, 
Running header: Maintaining masculinities

which as Manzenreiter (2013) and Mizuno (2002) also maintain, acts a mundane structuring of a man's surfing world.

Conversations with Kansai area surfers who have left the region often talk about this territoriality in frustration and sometimes anger, describing this closely knitted network as semai, referring to a sense of feeling confined within a small space. Several interviewees described stories of surf breaks policed by violence, rumours of violence, and the presence of Yakuza. In several cases people moved away from the area to avoid the restrictive social governance, while others were forced to leave due to more aggressive pressure. This tradition of nawabari ishiki is today reinforced and entangled with a particular masculine gender order in a place where the dominance of local surfer's is most revered, the North Shore on Oahu, Hawai'i.

\section{Japanese 'ohana: North Shore_Wakayama networks}

Surfing's social capital in the region of this study is commonly expressed by the number of winters one has spent in Hawai'i and the relationships established there. For instance, in the first conversation with a surf boss named Hiro he mentioned he has been travelling to Hawai'i for 45-years. His first-trip to Hawai'i was in 1972 and the following year he opened one of the earliest surf shops named after his favourite Hawaiian surf break. Another influential surf boss in Wakayama has spent 35 winters on the North Shore, mostly "surfing big waves at Waimea" (Waimea being a globally-honoured big wave surfing location). He identifies as a big wave surfer, and specialises in selling big wave "guns" made in Hawai'i, as well as shaping his own for the domestic market. For many first-generation surfers, Hawai'i is an integral part of their identities; materially through surf shop names, embodied in Hawai'i inspired tattoos, and through mobile ideologies of local pride and respect.

Recent Japanese language films like Wakita Peak (2018) push the idea that Japanese and Indigenous Hawaiian surf culture share entangled expressions of masculinity through ideas of 'honour', 'pride,' and 'respect.' The documentary positions professional surfer Takayuki Wakita as an exemplary case for how to gain respect in the North Shore. Wakita is characterised as patient, quietly working his way up the 'pecking order' through deference to the local surfers, dedicated to developing the skill of surfing big waves, and 'charging' risky waves that even the locals do not often surf, hence the name Wakita's Peak. The narrative culminates in a final scene where Wakita is invited to compete in the prestigious Eddie Aikau Big Wave Invitational under the Indigenous Hawai'ian national flag. Team Japan's recent 
Running header: Maintaining masculinities

participation in the invitation-only Da Hui Backdoor Shoot out in Memory of Duke Kahanamoku Invitational in 2018 and 2019 - an Indigenous-led surfing competition - saw the following commentary by a respected Hawaiian surfer: "Honour, respect, all I know, that's what Japanese 'ohana is, kind of our style, loyal and all that good stuff...what would Hawaii be without the Japanese" (Surfline, January 16, 2018). Wakayama and Kansai area surfers forefront cultural similarities with claims like "Samurai reigi [manners, courtesy, etiquette] and aloha are the same". Although it is beyond the scope of this study to offer a full understanding of how this cultural relationship is perceived in Hawai'i and its historical complexities, we can draw insights into how it functions to maintain masculine structures in Japan's surfscape.

When the first-generation Japanese surfers began travelling to Hawai'i in the 1970s they arrived at a significant political juncture, the Hawai'ian renaissance that sought to restore Indigenous language and culture (Walker 2011). An important component of the cultural movement transpired in the surf zone (Walker 2011, Ingersoll, 2016). Walker (2011) argues the surf zone was a critical space of resistance to the corporatisation of the North Shore of Oahu by the global surf industry. The surf zone became a tool for expressing renewed Hawaiian masculinities that "emphasised an identity based on a strong sense of local pride and respect" (Walker, 2011: 157). Similar to the Japanese concepts of territorial consciousness (nawabari ishiki) and the primacy of maintaining hierarchal relationships (joge kankei) discussed earlier, throughout most of Oceania social systems focus on the relational space connecting people (Walker, 2010). Like Japan, the surf scene is considered a relational space for maintaining social hierarchy and order both in and out of the water. Walker (2011) suggests this means "in both ancient and modern times, Hawaiian surfers have placed a high value on the notion of respect (p. 18)." The social, political and religious ordering of precolonial Hawai'i through the kapu system shares a similar emphasis on social hierarchy whereby commoners are required to show deference because of the chief's greater 'mana' (Fermantez, 2007). Through these vertical hierarchies a linkage-liked organisation is formed both domestically and abroad. 'Respect' refers to the recognition of specific status markers and hierarchy based on one's genealogy and socio-political rank (Walker 2011). Conflict arises from a lack of acknowledgement or disregard of this relational ontology.

Bringing together Walker's (2011) work on masculinity, surfers and the Hawaiian renaissance, with the Japanese surf culture discussed throughout this article we begin to see expressive and discursive convergences about masculine "pride, honour and respect". Palmer (2017) study on surfing in Brazil suggests the longstanding transnational flows between 
Running header: Maintaining masculinities

Brazilian and indigenous Hawaiian surfers is source of post-colonial identity and resistance. This also partially the case in Wakayama. However, we will now examine how the related locale of North Shore Hawai'i exemplifies how conservative gender relations may also be shored up through such transnational flows.

\section{Transnationalising 'respect', circulating surfing masculinities}

In the contrast to others who argue that trans-local surf mobilities "actively displace local and national ways of life...trans-local surfing identity works to undermine the local coingredient relations surfers value in their own backyards" (Anderson, 2014: 237), Wakayama's longstanding connections with its related locale of Hawai'i North Shore exemplifies how arrangements may be reinforced and maintained through transnational flows. Evidence of the transnational localism manifest in Wakayama can be seen at the Umi no Gakko [School of the Ocean] event that was held on June, 30, 2018. This event was particularly timely, as all the members of Team Japan who participated in the Da Hui Shootout earlier that year were in attendance. The following day was the annual Aloha Heaven event that featured a film slide show and interviews with the members of Team Japan at the 2018 Da Hui Backdoor Shootout and a founding member of the original Hui o He'e Nalu as a special guest. 2018 saw an increasingly visible Indigenous Hawaiian surf identity being expressed in the local Wakayama surfscape, of which Umi no Gakko was a part.

The foundation for Umi no Gakko has its origins in the Indigenous Hawaiian surf culture of the North Shore. Umi no Gakko emerged out of intergenerational networks spanning over four decades with North Shore Hawai'i and is the result of embodied experiences of second-generation Japanese surfers committing themselves to surfing North Shore's big waves. Kazu describes the influence the North Shore and how it has shaped his attitude towards the ocean, surfing, and his understanding of localism stating, "Hawaiian localism is best... If you give respect you get respect back... But it's not only a human thing, its nature...This is respect. Hawaiian surfing is about respect for the ocean, helping others, kindness, patience." This contrasts with other surf sites in Japan where the feminisation of beach culture has seen global brands like Quicksilver/Roxy reshaping Japan's coastlines (Doering 2018a), and the International Olympic Committee's efforts to encourage gender equality in competitive surfing during the Tokyo Olympics (Wheaton \& Thorpe, 2018). 
Running header: Maintaining masculinities

Wakayama's transnational surfscape manifests through an articulation powerfully informed by Indigenous Hawaiian cultural representations and ideologies.

The photograph in Figure 2 was taken during the 2018 Umi no Gakko event held at Isonoura Beach Park.

\section{$<$ INSERT FIGURE 2>}

The photo shows the variety of Indigenous Hawaiian cultural expressions currently unfolding on Wakayama's beaches. In addition to the hula dancers, the bottom left corner reveals one of around twenty volunteers who decided to wear bright yellow Hui o He'e Nalu t-shirts. This came as a surprise to some of the other volunteers, with one member of the Wakayama Surf Association saying he was also surprised of Hui o He'e Nalu presence at the event as this kind of unofficial sponsorship was not discussed with the wider surf community. In the topright, just above the Hula dancers, is a RealBvoice sponsorship flag. Connected with Da Hui, RealBvoice is a popular Japanese-based company that aims to convey the waterman tradition they have learned from one of the founding members of the original Hui o He'e Nalu (sometimes nicknamed 'Da Hui'), Buffalo Kaeulana located in Mākaha, Oahu. According to the company's website, the aim of the brand is "To convey the 'true Buffalo voice' to the world and to the future..." [author translation]. Figure 3 shows a RealBvoice slogan and logo pinned upon a large Indigenous Hawai'ian flag at the surf shop just down the beach from the event offering further visual expressions of social relations between Wakayama and Hawaiian surf cultures.

\section{<INSERT FIGURE 3>}

Recent discussions at the Wakayama Surfing Association have Wakayama's Isonoura Beach Park a Sister-City affiliation with Mākaha. Mākaha is renowned for its great surf but is also an important site of traditional Hawaiian arts and cultural programs that aim to preserve Indigenous Hawaiian traditions. The preservation of traditional culture being the primary aim. Here we have a desire by influential figures in the Wakayama and Kansai area surf community to refashion place and identity based on Indigenous Hawaiian surf culture (Fermantez, 2007).

Interestingly, second-generation surfers responsible for establishing Umi no Gakko are expressing a desire to open-up and diversify the once closed beach culture practiced by 
Running header: Maintaining masculinities

first-generation surfers in the area. Compared with the strict local governance first-generation surfers, the young influential surfers are considered community and family-centred, internationally networked, and open to new ideas. This corresponds with Comer's (2010, p. 173) Northern California female surf community who "take their lead from the late queen of Makaha, the Hawaiian Rell Sunn", community-mindedness, the spirit of public service, love of family and respect for the ocean are also emphasised in Wakayama thanks to these networks. The younger-generation of influential surfers in the area describe wanting to establish a local activism-based surf culture similar to that found on the North Shore in an effort to re-establish the island nation's once strong bonds with the sea. It was further argued throughout several conversations that strong local pride and collective voice is required if any changes are to be made against the ongoing industrialisation and cement fortification of the Japanese coastline. With a focus on local pride and strength, the Da Hui affiliation was described as compatible with Wakayama's traditional culture.

These transnational expressions of surf masculinities raises important questions concerning the shifting gender relations in the area. First and most obvious thing to note is that this reinforces already existing domestic masculine ideologies and practices associated with "local respect". One of the most circulated and popular images of the event for the local surf community was a re-enactment mimicking the iconic photo of the original Hui o He'e Nalu "black short" members posing at Waimea Bay in the late 1970s (see Walker 2011, p. 138). Shirtless, arms crossed in a defensive demeanour, all wearing "black shorts" - the group of ten influential surfers in the area reaffirming a patriarchal mode of surf break governance. The Indigenous Hawai'ian masculinity articulated in Wakayama aligns well with the existent patriarchal networks described earlier, contemporising cultural concepts of territoriality [nawabari ishiki], social hierarchy [joge kankei] into a transnational discourse of 'local respect.' However, once again, the key actors in the emerging story have all been male. A consequence is the continuing social and discursive subordination of women in the surf discourse and the reproduction of the masculine surf subject as the model for others to follow. The transnational male networks and hierarchies maintain a social structure that occlude women. This is a story of Japanese surf manhood, of making it on the North Shore, of becoming 'ohana, and of maintaining respect for "the local". At the local and regional levels, when considered through the lens of domestic gender relations, the transnational networks forged between Wakayama and Indigenous Hawaiian surf cultures could in part be understood to shore up the patriarchal surfscapes Mizuno $(2002,2018)$ has previously identified. 
Running header: Maintaining masculinities

\section{Conclusions: Maintaining masculinities in Japan's transnational surfscapes}

The study of surfing offers a useful lens for examining shifting sport-gender relations in Japan. The male-dominated networks noted in this study extend far beyond the surf, but one thing we learn from this example is how entrenched local and regional production of gender roles operate through transnational discourses and practices. While some suggest that trans-local surf mobilities actively displace local and national ways of life (Anderson, 2014), the study presented in this article argues the opposite: transnational surf networks may also reinforce existing social orders. The sports literature in Japan frequently points out that hidden behind the transcultural imagery promoted in other imported sports are a highly conservative and hegemonic discourses and practices that are proving difficult to overcome in Japan (Hinch et al., 2018; Light, 2008; Light at al., 2008). This study confirms that lifestyle sports in Japan follow a similar trend. On the other hand, it also highlights the importance and influence of non-Western transnational social networks in the making and re-making of surfing's global imaginaries. Mind you, more research is need to offer nuanced insight into how these transnational relationships (e.g. between Hawaii and Japan) play out at different sites, including the North Shore itself. New, distinctive global connections are emerging in the lifestyle sports world which are deserving of further attention.

One apprehension we have is that the Tokyo 2020 Olympics, backed by the global surf cultural industry dominated by white western interests, will detract attention away from the emerging importance of these non-Western social networks. It has been argued that the incorporation of surfing into the Olympics may be a vehicle to open up the conservative male dominated networks to difference, such as more and better access for women (Wheaton \& Thorpe, 2018). That is certainly one possibility. Yet, a widening of participation and increased transnational flows may actually serve to reinforce dominant local arrangements and contain change. Inclusion in the Olympics may in some circumstances prevent the "carving out" of new possibilities. 
Running header: Maintaining masculinities

\section{References}

Anderson, J. (2014). Surfing between the local and the global: Identifying spatial divisions in surfing practice. Transactions of the Institute of British Geographers, 39(2), 237-249.

Appadurai, A. (1996). Modernity at large: cultural dimensions of globalization. Minneapolis: University of Minnesota Press.

Austin, I. P. (2009). Common Foundations of American and East Asian Modernisation: From Alexander Hamilton to Junichero Koizumi. Singapore: Select Publishing.

Bandeira, M. M. (2014). Territorial disputes, identity conflicts, and violence in surfing. Motriz: Revista de Educação Física, 20, 16-25.

Beach Combing Magazine, (2018). Wakayama (pp. 152-157). Japan: Rise System Inc.

Braun, V., Clarke, V., \& Weate, P. (2016). Using thematic analysis in sport and exercise research. In B. Smith \& A. C. Sparkes (Eds.), Routledge Handbook of Qualitative Research in Sport and Exercise (pp. 191-205). London: Routledge.

Buckley, R. (2002). Surf tourism and sustainable development in Indo-Pacific Islands. I. The industry and the islands. Journal of sustainable tourism, 10(5), 405-424.

Clark, J. R. (2011). Hawaiian surfing: Traditions from the past. Honolulu: University of Hawai'i Press.

Comer, K. (2010). Surfer Girls in the New World Order. Durham: Duke University Press.

Comley, C. (2016). "We have to establish our territory": how women surfers 'carve out' gendered spaces within surfing. Sport in Society, 19(8-9), 1289-1298.

Connell, R. W. (1995). Masculinities. Berkeley and Los Angeles: University of California Press.

De Alessi, M. (2009). The customs and culture of surfing, and an opportunity for a new territorialism. Reef Journal, 1(1), 85-92.

Doering, A. (2018a). Mobilising Stoke: A Genealogy of Surf Tourism Development in Miyazaki, Japan. Tourism Planning \& Development, 15(1), 68-81.

Doering, A. (2018b). From he'e nalu to Olympic sport: A century of surfing evolution (case study). In J. Higham, \& T. Hinch, Sport Tourism Development (3rd edition), (pp. 200203). Bristol, UK: Channel View Publications.

Evers, C. (2006). How to surf. Journal of Sport and Social Issues, 30(3), 229-243.

Evers, C. (2009). The point: Surfing, geography and a sensual life of men and masculinity on the Gold Coast, Australia. Social and Cultural Geography, 10(8), 893-908.

Evers, C. (2017). Surfing and contemporary China. In D. Z. Hough-Snee \& A. S. Eastman (Eds.), The Critical Surf Studies Reader (pp. 387-402). Durham: Duke University Press.

Evers, C. (2016). Researching action sport with a GoPro camera: An embodied and emotional mobile video tale of the sea, masculinity and men-who-surf. In I. Wellard (Ed.), 
Running header: Maintaining masculinities

Researching embodied sport: Exploring movement cultures (pp. 145-162). London: Routledge.

Evers, C. (2018). The gendered emotional labor of male professional 'freesurfers' digital media work. Sport in Society, Online first. DOI: 10.1080/17430437.2018.1441009

Fendt, L. S., \& Wilson, E. (2012). 'I just push through the barriers because I live for surfing': how women negotiate their constraints to surf tourism. Annals of Leisure Research, 15(1), 4-18.

Fermantez, K. (2007). Between The Hui and Da Hui Inc.: Incorporating N-oceans of Native Hawaiian Resistance in Oceanic Cultural Studies. Indigenous Encounters: Reflections on Relations between People in the Pacific, 43, 85-99.

Ford, N., \& Brown, D. (2006). Surfing and Social Theory: experience, embodiment, and narrative of the dream glide. London: Routledge.

Gilio-Whitaker, D. (2017). Appropriating Surfing and the Politics of Indigenous Authenticity. In D. Z. Hough-Snee \& A. S. Eastman (Eds.), The Critical Surf Studies Reader (pp. 214-232). Durham: Duke University Press.

Hinch, T., Higham, J., \& Doering, A. (2018). Sport, tourism and identity: Japan, rugby Union and the transcultutral maul. In C. Acton \& D. Hassan (Eds.), Sport and Contested Identities: Contemporary Issues and Debates (pp. 191-206). London: Routledge.

Hough-Snee, D. Z. (2015). "You have the right to surf!": Riding waves of modernity, decolonization, and national identity in Peru. In H. F. L'Hoeste, R. Irwin, \& J. Poblete (Eds.), Sports and nationalism in Latin/o America (pp. 201-223). New York: Palgrave MacMillan.

Hough-Snee, D. Z., \& Eastman, A. S. (2017). The Critical Surf Studies Reader. Durham: Duke University Press.

Ingersoll, K. A. (2016). Waves of Knowing: A Seascape Epistemology. Durham: Duke University Press.

Iwata, H. (2010). Wakayama Isonoura ni okeru,sāfin wo toshita machitzukuri kenkyu: Sāfano ishiki chōsa kara meite kuru mono [A study of community development through surfing in Isonoura Beach, Wakayama: Lessons learned from a survey of surfers]. Paper presented at The $2^{\text {nd }}$ Surf Science and Technology Symposium, Kanagawa Kenritsu Josei Sentā, Yokohama, February 14.

Kanagawa, A. (2018). Nihonjin no 'umi hanare' ga tomaranai riyū [The reasons why the Japanese cannot stop 'sea departure']. Retrieved July 29, 2018, from The Yomiuri Shimbun www.yomiuri.co.jp/fukayomi/ichiran/20180705-OYT8T50008.html

Knijnik, J. D., Horton, P., \& Cruz, L. O. (2010). Rhizomatic bodies, gendered waves: transitional femininities in Brazilian Surf. Sport in Society, 13(7-8), 1170-1185.

Kobayashi, K. (2013). Kugenumakaigan de no sāfin no hasshō zenshi [The early history of surfing along the Kugenuma coast]. Bunkyo University Journal of the Faculty of International Studies, 23(2), 1-11. 
Running header: Maintaining masculinities

Kobayashi, K., Nishida, R., \& Matsumoto, H. (2011). Chigasaki-shi no sāfin kanren sangyō no hasshō to suii [The origin and history of industries related to surfing in Chigasaki City]. Shōnan Forum, 16, 107-118.

Kobayashi, K., Nishida, R., \& Matsumoto, H. (2012). Nījima ni okeru sāfin ni yoru kankō yūchi no ikisatsu [The historical details of attracting tourists to Niijima island with surfing]. Bunkyo University Journal of the Faculty of International Studies, 22(2), 13 24.

Konagaya, Y. (2005). Nihon ni okeru safin no juyo katei [The diffusion process of modern surfing in Japan]. Rikkyo University School of Tourism Bulletin, 7, 1-16.

Konagaya, Y. (2009). Safuin bunka no keisei to kukan to iu media [Development of surfing culture and media space]. In K. Kanda (Ed.), Rejya no kukan: shosō to apurōchi (pp. 59-67). Kyoto, Japan: Nakanishiya.

Laderman, S. (2014). Empire in waves: A political history of surfing. Berkeley: University of California Press.

Laderman, S. (2016). Wanderlust: surfing, modernization, and cultural diplomacy in the long 1970s. Diplomatic History, 40(5), 865-884

Light, R. (2008). Learning masculinities in a Japanese high school rugby club. Sport, Education and Society, 13(2), 163-179.

Light, R., Hirai, H., \& Ebishima, H. (2008). Tradition, identity professionalism and tensions in Japanese rugby. In G. Ryan (Ed.), The Changing Faces of Rugby: The Union Game and Professionalism since 1995 (pp. 147-164). Newcastle: Cambridge.

lisahunter. (2018). Surfing, Sex, Genders and Sexualities. Abingdon: Routledge.

McVeigh, B. J. (2013). The Nature of the Japanese State: Rationality and Rituality. London: Routledge.

Manzenreiter, W. (2013). No pain, no gain: embodied masculinities and lifestyle sport in Japan. Contemporary Japan, 25(2), 215-236.

Massey, D. (1994). Space, Place, and Gender. Minneapolis: University of Minnesota Press.

McDonald, T. H. (2018). Conceptualizing an Ethology of Masculinities: Do We Know What Masculinities Can Do? Men and Masculinities, 21(1), 56-71.

McGloin, C. (2017). Indigenous Surfing: Pedagogy, Pleasure, and Decolonial Practice. In D. Z. Hough-Snee \& A. S. Eastman (Eds.), The Critical Surf Studies Reader (pp. 196213). Durham: Duke University Press.

Mizuno, E. (2002). Supōtsu to kaibunka ni tsuite no ichikōsatsu: X sāfu shoppu ni mirareru dansei bun [A study on sports and subculture: 'Male culture' at surf shop X]. Kyoto Journal of Sociology, 10, 35-60.

Mizuno, E. (2007). Supōtsu to kanyō-sei: sāfin kyōdōtai ni okeru jendā to rōkarizumu [Sports and tolerance: gender and localism in surfing communities]. In S. Ashina (Ed.), Tagenteki sekai ni okeru kanyō to kōkyō-sei: Higashiajia no shiten kara (pp. 198-214). Kyoto: Koyo Shobō. 
Running header: Maintaining masculinities

Mizuno, E. (2015). Nihon ni okeru sāfin o suru josei no 50-nen (1): 1990-nen ikō no sāfin bunka to jendā kōhei [50 years of women surfing in Japan (1): Surfing culture and gender equity since the 1990's]. Journal of the University of Marketing and Distribution Sciences:Humanities, arts and Sciences, 28(1), 53-76.

Mizuno, E. (2018). Multiple marginalization?: representation and experience of bodyboarding in Japan. Surfing, Sex, Genders and Sexualities (pp. 89-108). New York: Routledge.

Moore, M. S. (2010). Sweetness and Blood: How Surfing Spread from Hawaii and California to the Rest of the World, with Some Unexpected Results. New York: Rodale.

Murata, S. (2017). Kūkan funsō to shite no jizoku-teki supōtsutsūrizumu: Jizoku-teki kaihatsu ga kataranai chiiki no seikatsu-shi [Sustainable sports tourism as a spatial conflict: Documenting the local life that sustainable development does not talk about]. Tokyo: Shinyosha.

Nakano, S. (2018). Kinki, Shikoku eria no nami tippusu [Surfing tips for Kinki and Shikoku areas]. Surftrip Journal, 92, 52-61.

O’Brien, D., \& Ponting, J. (2013). Sustainable surf tourism: A community centered approach in Papua New Guinea. Journal of Sport Management, 27(2), 158-172.

Ohkawa, N. (2007). Traditional surfing in Japan: an unknown history. Retrieved April 14, 2016, from http://www.nobbywoodsurfboards.com

Olive, R. (2016). Women who surf: Female difference, intersecting subjectivities and cultural pedagogies. In A. Hickey (Ed.), The Pedagogies of Cultural Studies (pp. 197-213). London: Routledge.

Olive, R., McCuaig, L., \& Phillips, M. G. (2015). Women's recreational surfing: a patronising experience, Sport, Education and Society, 20:2, 258-276

Olive, R., Thorpe, H., Roy, G., Nemani, M., Wheaton, B., \& Humberstone, B. (2016). Surfing together: Exploring the potential of a collaborative ethnographic moment Women in Action Sport Cultures (pp. 45-68): Springer.

Palmer, C. (2017). The Brazilian Hawaii: Surf culture, tourism, and the construction of place. Global Ethnographic, 4, 1-10.

Ponting, J. (2017). Simulating nirvana: surf parks, surfing spaces, and sustainability. In G. Borne \& J. Ponting (Eds.), Sustainable Surfing (pp. 219-237). Abingdon: Routledge.

Roy, G. (2014). Taking emotions seriously: Feeling female and becoming-surfer through UK Surf Space. Emotion, Space and Society, 12, 41-48.

Smith, B. (2018) Generalizability in qualitative research: misunderstandings, opportunities and recommendations for the sport and exercise sciences. Qualitative Research in Sport, Exercise and Health, 10(1), 137-149.

Stebbins, R. A. (1982). Serious leisure: A conceptual statement. Pacific Sociological Review, 25(2), 251-272. 
Running header: Maintaining masculinities

Surfline (January16, 2018). Da Hui Backdoor Shootout Day 5. Online http://www.surfline.com/video/contests/da-hui-backdoor-shootout-final-dayreplay_151449

Thompson, G. (2017). Pushing under the whitewash: Revisiting the making of South Africa's surfing sixties. In D. Z. Hough-Snee \& A. S. Eastman (Eds.), The Critical Surf Studies Reader (pp. 155-176). Durham: Duke University Press.

Thorpe, H. (2014). Transnational mobilities in action sport cultures. London: Palgrave Macmillan.

Thorpe, H., \& Olive, R. (2016). Women in Action Sport Cultures: Identity, Politics and Experience. London: Palgrave Macmillan.

Usher, L. E., \& Kerstetter, D. (2015). Surfistas locales: transnationalism and the construction of surfer identity in Nicaragua. Journal of Sport and Social Issues, 39(6), 455-479.

Usher, L. E., \& Gómez, E. (2016). Surf localism in Costa Rica: Exploring territoriality among Costa Rican and foreign resident surfers. Journal of Sport \& Tourism, 20(3-4), 195-216.

Waitt, G., \& Warren, A. (2008). 'Talking shit over a brew after a good session with your mates': Surfing, space and masculinity. Australian Geographer, 39(3), 353-365.

Walker, I. H. (2011). Waves of resistance: Surfing and history in twentieth-century Hawaii. Honolulu: University of Hawai'i Press.

Warren, A. \& Gibson, C. (2014). Surfing Places, Surfboard Makers: Craft, Creativity, and Cultural heritage in Hawai'i, California, and Australia. Honolulu: University of Hawai'i Press.

Warshaw, M. (2010). The history of surfing. San Francisco: Chronicle Books.

Westwick, P., \& Neushul, P. (2013). The world in the curl: An unconventional history of surfing. New York: Crown.

Watson, J. (2015). Multiple mutating masculinities. Angelaki, 20(1), 107-121.

Wheaton, B. (2013). The Cultural Politics of Lifestyle Sports. Abingdon: Routledge.

Wheaton, B., \& Thorpe, H. (2018). Action Sports, the Olympic Games, and the Opportunities and Challenges for Gender Equity: The Cases of Surfing and Skateboarding. Journal of Sport and Social Issues, 42(5), 315-342.

Yaguchi, Y., \& Yoshihara, M. (2004). Evolutions of "Paradise": Japanese tourist discourse about Hawai'i. American Studies, 45(3), 81-106. 
Running header: Maintaining masculinities

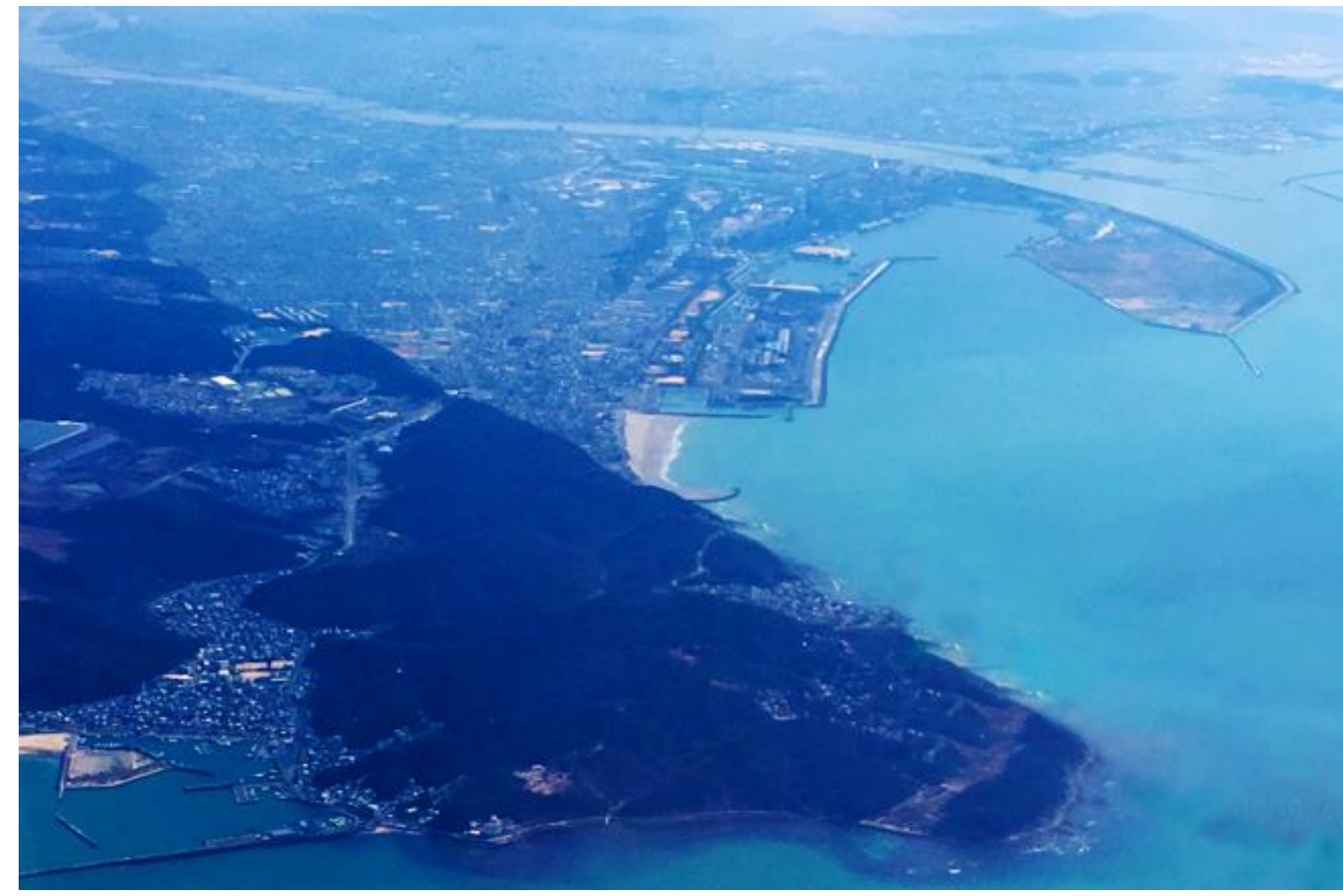

Figure 1: Isonoura Beach, Wakayama. The birthplace of surfing in the Kansai region. Photo by first author. 


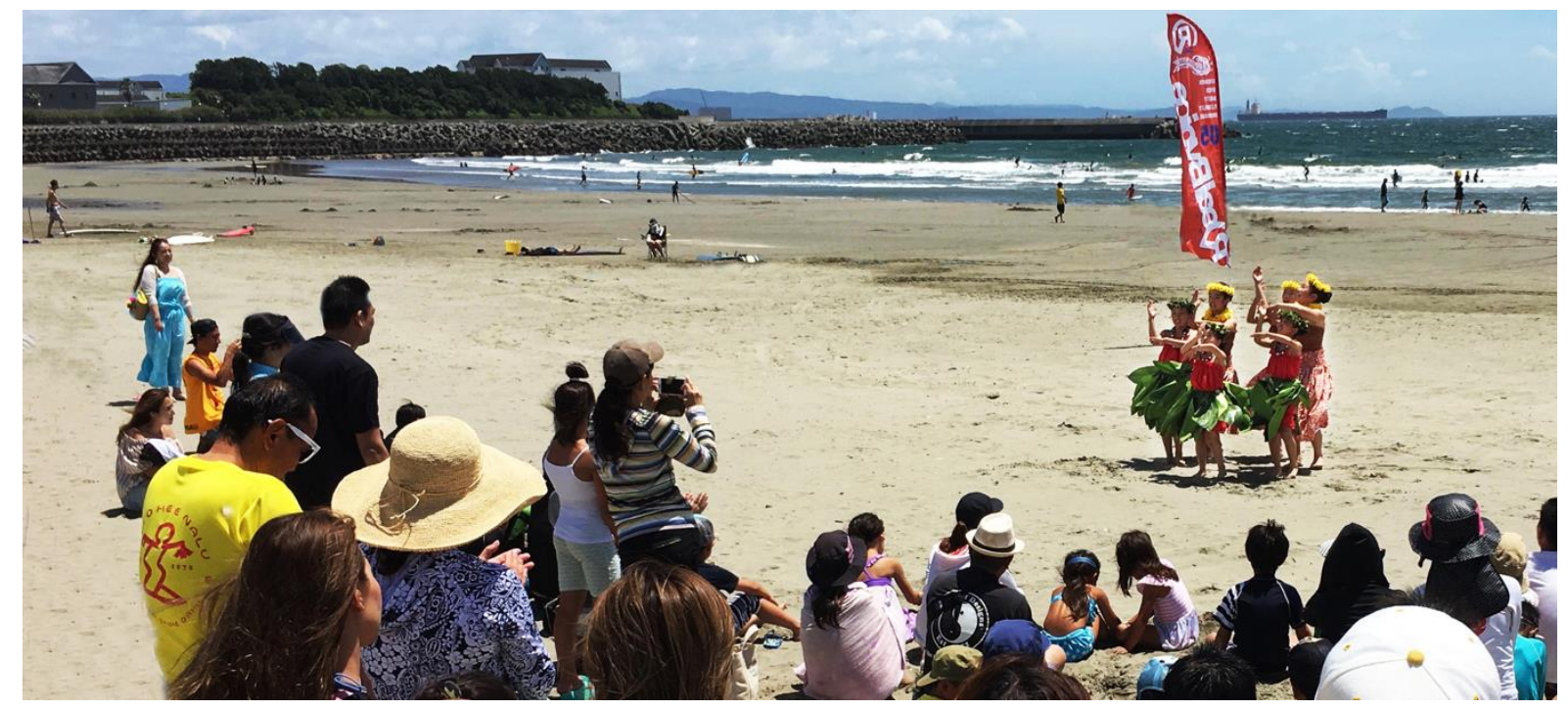

Figure 2. Indigenous Hawaiian representation at Umi no Gakko. Isonoura beach, June 30, 2018. Photo by first author. 
Running header: Maintaining masculinities

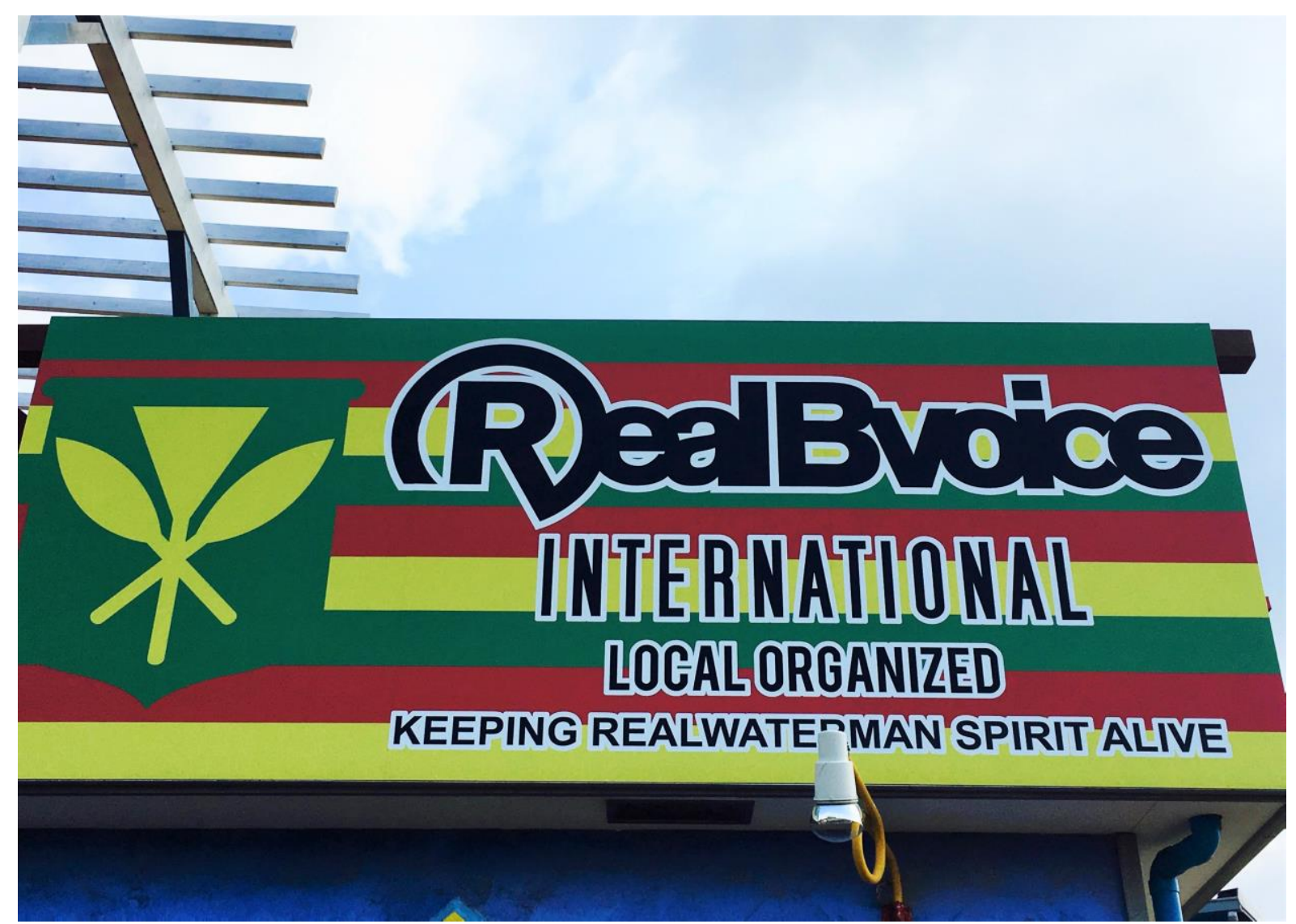

Figure 3. Indigenous Hawaiian expressions on local surf shop signage. Photo by first author. 
Running header: Maintaining masculinities

\footnotetext{
${ }^{1}$ The Kantō region includes the Greater Tokyo Area and seven prefectures including the popular coastal areas of Chiba, Ibaraki, and Kanagawa, where the popular surf beaches in Shōnan are located and the Olympic site at Ichinomiya in Chiba.

${ }^{2}$ See Kawa no me, Eye Symmetry, 2015; Real Axe: Japan, Billabong, 2015; Billabong Bloodlines: Japan, Billabong, 2016; The Typhoon, RipCurl, 2018. Exceptions to this include Red Bull's (2007) [DVD]. Tai Fu The Art of Surfing A Typhoon Swell featuring father and son Wakayama big-wave surfers Genki Horiguchi and Shinpei Horiguchi.

${ }^{3}$ This is a more dynamic interpretation of masculinities than the popular social construction model introduced by Connell's theory (1995).

${ }^{4}$ Localism is a hierarchical territorialisation policed by violence (or the threat of) and particularly gendered cultural codes in regards to skill, spatial sensibilities, and belonging (for instance, see Bandeira, 2014; Evers, 2009; Olive, 2016; Usher \& Gómez 2016).

5 This supports Ingersoll's (2016) argument that surf tourism definitions are Western-orientated and fail to consider how other cultures travel the seascapes in different ways.

${ }^{6}$ All names are pseudonyms.

${ }^{7}$ The ways contemporary surfing communities continue to be informed by histories and practices related to fishing is an interesting area of study deserving of further attention, particularly within Asian contexts. See De Alessi's (2009) discussion of surfing culture's parallels with fishery territoriality and Murata's (2017) discussion of the conflicts between surfing and fishing industries as a starting point for further exploration.
} 